\title{
The impact of ARUBA on the clinical practice of unruptured brain arteriovenous malformations: big data, poor evidence and measuring impact on health policy
}

\author{
Victor Volovici ${ }^{1}$ (1) Torstein R. Meling ${ }^{2,3}$
}

Received: 1 July 2021 / Accepted: 6 July 2021 / Published online: 20 July 2021

(c) The Author(s), under exclusive licence to Springer-Verlag GmbH Austria, part of Springer Nature 2021

Unruptured brain arteriovenous malformations (bAVMs) are rare entities with an incidence estimated at 0.6-1.4/100, 000 person-years [9]. These lesions most often present with epileptic seizures or intracranial hemorrhage. Due to the rarity of the disease, reliable longitudinal population cohort studies are lacking. Best estimates of the yearly risk of hemorrhage are often based on underpowered or heavily selected cohorts with a low event rate $[8,9]$. Because of the higher risk of hemorrhage of ruptured bAVMs, treatment is usually mandatory, either through microsurgery, radiotherapy, or endovascular means. However, treatment of unruptured bAVMs has been debated for some years, in part because of the poor natural history data available.

A Randomized trial of Unruptured Brain Arteriovenous malformations (ARUBA), originally published in 2014 with updated results of the last follow-up published in 2020 [7], randomized patients to either receive an intervention or medical management. The trial has undergone fierce criticism given its inflated causal claims based on very limited external validity $[6,12]$. In fact, the results of the ARUBA trial intervention arm are some of the poorest in the entire scientific literature, making ARUBA an outlier. As such, the

This article is part of the Topical Collection on Vascular Neurosurgery Arteriovenous

Victor Volovici

v.volovici@erasmusmc.nl

1 Department of Neurosurgery, Erasmus MC Stroke Center, Erasmus MC University Medical Center, Rotterdam, The Netherlands

2 Division of Neurosurgery, Department of Clinical Neurosciences, Geneva University Hospitals, Geneva, Switzerland

3 Faculty of Medicine, University of Geneva, Geneva, Switzerland implications of the trial on clinical practice should be very little to none.

After the original 2014 publication in The Lancet, various groups have published several treatment results from retrospective single-center patient cohorts harboring unruptured bAVMs [10]. These publications, albeit of equally low scientific value, serve to further strengthen the idea that the results of the ARUBA are outliers and not an accurate reflection of the complication rates incumbent to the various techniques [10].

To date, two scientific analyses dissect the issue of the impact of the ARUBA trial on clinical practice, in particular in the USA $[1,11]$. Birnbaum and colleagues queried the Nationwide Inpatient Sample (NIS) database up to the end of 2015. The NIS was created by the Healthcare Cost and Utilization Project (HCUP), and this database samples roughly 5 to 7 million hospitalized patients yearly, representing $20 \%$ of all discharges annually. It is the largest public national all-payer database and is sponsored by the Agency for Healthcare Research and Quality (AHRQ). Birnbaum et al. [1] came to the conclusion that even though the number of treated unruptured bAVMs seemed to decrease, the rate of microsurgically treated bAVMs increased.

Reynolds and colleagues queried the National Readmissions Database, an HCUP database that is used to estimate readmission data, until the end of 2015 [11]. As per HCUP, National Readmission Database excludes rehabilitation and long-term acute care hospitals, unlike the NIS [11]. The authors found that there was no significant change in the rates of intervention for unruptured bAVMs in the period after ARUBA, compared to the period before ARUBA.

In the latest issue of Acta Neurochirurgica, Wahood and colleagues query the NIS from 2006 to the end of 2018 and find that the rates of intervention decreased overall, only endovascular therapy remaining at the pre-ARUBA level. They explain the discrepancy with previous research endeavors through the use of a different time period (both previous 
publications used data until 2015) and the use of different ICD codes. The new analysis uses a combination of ICD-9 and ICD-10 codes, while the previous two publications used ICD-9 codes. In terms of analysis, Birnbaum et al. [1] used simple inference tests, whereas Reynolds et al. and Wahood et al. used join-point regression to make sense of the (to a certain extent autocorrelated) time series data. None of the papers used adjustment for multiple correction or propensity-adjusted regression discontinuity analysis, for example. The reason for the unadjusted analysis is the likely absence of disease-specific covariates in the dataset (such as location, anatomical details, grading). The NIS includes general variables about the patients and no disease-specific details. Furthermore, the NIS database has been subject to change over the course of several years, and numerous publications draw attention to the limits of drawing conclusion based on NIS samples $[4,5]$. With these considerations in mind, the question remains if the decline in unruptured bAVM treatment is real and, even more so, if the causal claim regarding the ARUBA influence holds.

Technical and methodological details aside, the research question at hand is highly relevant. Given that most referrals come from neurology departments, at least in Europe, where unruptured bAVMs are rarely referred directly to a vascular neurosurgeon, taking stock of the actual situation is paramount. Are treatment rates declining? And if they are, is it because of changing referral patterns due to ARUBA? A specially designated database, comprising at least European and US should be constituted. Big data and adequate methodology should be used to analyze the time series pre- and post-ARUBA and, if the effect is real and attributable to ARUBA, clinical practice guidelines should be discussed and re-evaluated in a multidisciplinary consensus $[2,3]$.

Trials with poor external validity cannot and should not be allowed to influence clinical practice. The duty of clinicians with expertise in treating patients harboring unruptured bAVMs is not only to carry on providing the best care to these patients based on the best available evidence, but also to prevent poor practice through overreliance on poor evidence [12].

If treatment rates of bAVMs have been affected by ARUBA, communication is the key - referral patterns should be discussed and clinical practice guidelines changed, for both neurologists and neurosurgeons. It is our responsibility to protect health policy from influences that originate from the misuse of poor evidence.

\section{References}

1. Birnbaum LA, Straight M, Hegde S, Lacci JV, de Leonni SM, Mascitelli JR, McDougall CM, Caron J-LR (2020) Microsurgery for unruptured cerebral arteriovenous malformations in the national inpatient sample is more common post-ARUBA. World Neurosurgery 137:e343-e346

2. Cenzato M, Boccardi E, Beghi E, Vajkoczy P, Szikora I, Motti E, Regli L, Raabe A, Eliava S, Gruber A, Meling TR, Niemela M, Pasqualin A, Golanov A, Karlsson B, Kemeny A, Liscak R, Lippitz B, Radatz M, LaCamera A, Chapot R, Islak C, Spelle L, Debernardi A, Agostoni E, Revay M, Morgan MK (2017) European Consensus Conference on Unruptured Brain AVMs Treatment (supported by EANS, ESMINT, EGKS, and SINCH). Acta Neurochir (Wien) 159(6):1059-1064

3. Feghali J, Huang J (2020) Updates in arteriovenous malformation management: the post-ARUBA era 5:34-39

4. Khera R, Angraal S, Couch T, Welsh JW, Nallamothu BK, Girotra S, Chan PS, Krumholz HM (2017) Adherence to methodological standards in research using the national inpatient sample. JAMA 318:2011-2018

5. Khera R, Krumholz HM (2017) With great power comes great responsibility: big data research from the national inpatient sample. Circ Cardiovasc Qual Outcomes 10(7):e003846

6. Meling TR, Proust F, Gruber A, Niemela M, Regli L, Roche PH, Vajkoczy P (2014) On apples, oranges, and ARUBA. Acta Neurochir (Wien) 156:1775-1779

7. Mohr JP, Overbey JR, Hartmann A, Kummer RV, Al-Shahi Salman R, Kim H, van der Worp HB, Parides MK, Stefani MA, Houdart E, Libman R, Pile-Spellman J, Harkness K, Cordonnier C, Moquete E, Biondi A, Klijn CJM, Stapf C, Moskowitz AJ (2020) Medical management with interventional therapy versus medical management alone for unruptured brain arteriovenous malformations (ARUBA): final follow-up of a multicentre, nonblinded, randomised controlled trial. The Lancet Neurology 19:573-581

8. Ondra SL, Troupp H, George ED, Schwab K (1990) The natural history of symptomatic arteriovenous malformations of the brain: a 24-year follow-up assessment. J Journal of Neurosurgery 73(3):387-391

9. Osbun JW, Reynolds MR, Barrow DL (2017) Arteriovenous malformations: epidemiology, clinical presentation, and diagnostic evaluation. Handb Clin Neurol 143:25-29

10. Peciu-Florianu I, Leroy HA, Drumez E, Dumot C, Aboukaïs R, Touzet G, Leclerc X, Blond S, Lejeune JP, Reyns N (2020) Radiosurgery for unruptured brain arteriovenous malformations in the pre-ARUBA era: long-term obliteration rate, risk of hemorrhage and functional outcomes. Sci Rep 10:21427

11. Reynolds AS, Chen ML, Merkler AE, Chatterjee A, Díaz I, Navi BB, Kamel H (2019) Effect of a randomized trial of unruptured brain arteriovenous malformation on interventional treatment rates for unruptured arteriovenous malformations. Cerebrovasc Dis 47:299-302

12. Volovici V, Schouten JW, Vajkoczy P, Dammers R, Meling TR (2021) Unruptured arteriovenous malformations 52:1143-1146

Publisher's note Springer Nature remains neutral with regard to jurisdictional claims in published maps and institutional affiliations. 